\title{
Sinopse do gênero Eucharassus Bates (Coleoptera, Cerambycidae)
}

\author{
Marcela L. Monné
}

\begin{abstract}
${ }^{1}$ Museu Nacional, Universidade Federal do Rio de Janeiro. Quinta da Boa Vista, São Cristovão, 20940-040 Rio de Janeiro-RJ, Brasil. mlmonne@uol.com.br
\end{abstract}

\begin{abstract}
Synopsis of the genus Eucharassus Bates (Coleoptera, Cerambycidae). The genus Eucharassus is redescribed and a key to the species is given. Four new species are described: Eucharassus hovorei sp. nov. and E. lingafelteri sp. nov. from Costa Rica, E. chemsaki sp. nov. from Panama and E. wappesi sp. nov. from Panama and Guatemala.

KEYWORDS. Cerambycinae; Necydalopsini; Neotropical; new species; taxonomy.

RESUMO. Sinopse do gênero Eucharassus Bates (Coleoptera, Cerambycidae). O gênero Eucharassus é redescrito e chave para as espécies é fornecida. São descritas quatro novas espécies: Eucharassus hovorei sp. nov. e E. lingafelteri $\mathbf{s p .}$ nov. da Costa Rica, E. chemsaki sp. nov. do Panamá e E. wappesi sp. nov. do Panamá e Guatemala.
\end{abstract}

PALAVRAS-CHAVE. Cerambycinae; Necydalopsini; Neotropical; novas espécies; taxonomia.

A tribo Necydalopsini Lacordaire, 1869 compreende, atualmente 206 espécies distribuídas em sete gêneros. Destes, apenas um não ocorre na região Neotropical: Conopogaster Fairmaire, 1899, gênero monotípico de Madagascar (Aurivillius 1912; Monné 2005). Dos seis gêneros neotropicais, Necydalopsis Blanchard, 1851 é o único na qual as espécies são andino-patagônicas, as espécies dos demais gêneros distribuem-se desde o México até a Argentina, a leste da cordilheira dos Andes.

Bates (1885) descreveu Eucharassus para E. dispar do Panamá e o considerou semelhante a Lissozodes Bates, 1870, à época alocado em Rhopalophorini Blanchard, 1845. Aurivillius (1891) descreveu E. nisseri da Colômbia, com dúvidas, em Eucharassus já que a espécie apresentava também caracteres de Lissozodes. Posteriormente, Aurivillius (1912) incluiu Eucharassus em Necydalopsini. Melzer (1934) descreveu $E$. bicolor e E. nevermanni provenientes do Vulcão Irazu na Costa Rica. Galileo \& Martins (2001) descreveram E. confusus da Venezuela e E. flavotibiale da Colômbia e forneceram chave para identificação das espécies.

As atuais seis espécies de Eucharassus distribuem-se na Costa Rica, Panamá, Colômbia e Venezuela (Monné 2005) e seu estudo permitiu o reconhecimento de quatro espécies novas, duas da Costa Rica, uma do Panamá e uma do Panamá e Guatemala, totalizando dez espécies no gênero. Eucharassus é redescrito e a chave para identificação das espécies de Galileo \& Martins (2001) é adaptada, para a inclusão das novas espécies.

As siglas mencionadas no texto correspondem: California Academy of Sciences, São Francisco, Califórnia, Estados Unidos (CASC); Essig Museum of Entomology, University of California, Berkeley, Califórnia, Estados Unidos (EMEC); Museu Nacional, Universidade Federal do Rio de Janeiro, Rio de Janeiro, Brasil (MNRJ); United States National Museum, Washington, Estados Unidos (USNM).

\section{Eucharassus Bates, 1885}

Eucharassus Bates, 1885: 308; Galileo \& Martins, 2001: 98; Monné, 2005: 402.

Espécie tipo. Eucharassus dispar Bates, 1885 por monotipia.

Fronte vertical e deprimida; margens laterais elevadas. Tubérculos anteníferos próximos entre si, elevados, separados por sulco e com ápices projetados. Olhos com granulação ocular média; ligação entre os lobos oculares estreita, no máximo, com três fileiras de omatídios; lobos oculares inferiores transversais e estreitos, cerca de três vezes mais largos que os lobos superiores. Genas intumescidas. Mandíbulas com ápices simples ou bidenteados. Artículo apical dos palpos maxilares atenuados na base e no ápice e dos labiais, cilíndricos. Antenas filiformes, nos machos mais longas que o corpo; escapo cilíndrico, engrossado; antenômeros III-XI com duas carenas longitudinais.

Protórax mais longo que largo; margem anterior mais larga que posterior. Lados do protórax, exceto margens anterior e posterior, e prosterno com dimorfismo sexual; nos machos distintamente intumescidos, com superfície opaca e pontos finos e densos; nas fêmeas, não intumescidos e sem pontos finos e densos. Pronoto com constrições, anterior e posterior; nas fêmeas, menos acentuada. Processo prosternal laminiforme. Cavidades procoxais angulosas aos lados e fechadas atrás. Processo mesosternal estreito, não laminiforme. Cavidades mesocoxais fechadas nos lados. Escutelo pouco mais longo que largo. Élitros inteiros ou com último tergito visível dorsalmente, pelo menos três vezes mais longo que o protórax; superfície microcorrugada e opaca. Pernas posteriores cerca de 1/3 mais longas que as anteriores; pro- e mesocoxas cônicas, projetadas; fêmures pedunculado-clavados; tíbias tão longas quanto os fêmures, sem carenas. 
Comentários. Entre os gêneros Neotropicais de Necydalopsini, Eucharassus assemelha-se à Lissozodes pelos seguintes caracteres: lobos oculares inferiores transversais e estreitos, antenômeros III-V não engrossados, protórax cilíndrico e sem tubérculos (exceto E. confusus Galileo \& Martins, 2001) e tíbias sem carenas. Eucharassus difere de Lissozodes por apresentar duas carenas longitudinais nos antenômeros III-XI e distinto dimorfismo sexual, nos machos os lados do protórax e o prosterno são intumescidos e com superfície pontuada e opaca. Em Lissozodes os antenômeros IV-XI apresentam apenas uma carena e os lados do protórax e o prosterno têm superfície pontuada e opaca mas não é intumescida.

Chave para as espécies de Eucharassus modificada de Galileo $\&$ Martins (2001):

1. Cabeça, protórax, mesosterno, metasterno e abdome com reflexo metálico azul ou verde ..................................... 2

Cabeça, protórax, mesosterno, metasterno e abdome sem reflexo metálico

2(1). Élitros com faixa longitudinal de pêlos dourados; tarsos unicolores, castanho-escuros ou pretos (Fig. 3). Costa Rica. E. hovorei sp. nov.

Élitros sem faixa de pêlos dourados; tarsômeros I-II castanho-escuros e III-V castanho-claros. (Fig. 4). Panamá . E. lingafelteri $\mathbf{s p . ~ n o v . ~}$

3(1). Fêmures unicolores, pretos 4 Fêmures bicolores, com a base amarelada e a metade apical preta ou castanha . 5

4(3). Fêmea: protórax, escutelo, mesepisterno e metasterno pretos ou castanho-avermelhados. Costa Rica E. nevermanni Melzer, 1934

Fêmea: protórax, escutelo, mesepisterno e metasterno avermelhados ou alaranjados. Panamá . E. dispar Bates, 1885

5(3). Élitros com três faixas transversais de pubescência dourada ou esbranquiçada contrastante com tegumento . 6

Élitros sem faixas transversais de pubescência contrastante. 7

6(5). Corpo com aspecto estreito. Élitros com faixas de pubescência dourada. Macho: margem posterior do protórax distintamente mais estreita que a anterior; antenômero XI tão longo quanto X. Fêmeas: antenas alcançam o terço apical dos élitros; antenômeros IIIIV com tufo de pêlos pretos na metade apical (Figs. 5, 6) Panamá, Guatemala ................... E. wappesi sp. nov. Corpo com aspecto robusto. Élitros com faixas de pubescência esbranquiçada. Macho: margem posterior do protórax ligeiramente mais estreita que a anterior; antenômero XI 1/3 mais longo que X.
Fêmeas: antenas alcançam o meio dos élitros; antenômeros III-IV sem tufo de pêlos (Figs. 1, 2). Costa Rica E. chemsaki sp. nov.

7(5). Pubescência elitral muito esparsa ou ausente; metatarsômeros pretos ............................................... 8

Pubescência elitral mais evidente; metatarsômeros amarelados 9

8(7). Fêmea: antenas atingem o terço apical dos élitros; pronoto avermelhado, élitros pretos, unicolores. Costa Rica E. bicolor Melzer, 1934

Fêmea: antenas alcançam ou apenas ultrapassam o ápice elitral; pronoto e élitros concolores, alaranjados, ou pronoto preto e élitros bicolores, pretos e amarelos. Colômbia, Equador.... E. nisseri Aurivillius, 1891

9(7). Macho: base dos antenômeros III-VII amarelados, apenas com pêlos longos; pronoto sem tubérculos, com superfície regular e uma elevação discreta subtransversal no nível do terço anterior. Colômbia E. flavotibiale Galileo \& Martins, 2001

Fêmea: antenas bicolores, avermelhadas, com pubescência e pêlos longos; pronoto com dois tubérculos ao nível do meio e duas gibosidades no nível do terço basal. Venezuela

E. confusus Galileo \& Martins, 2001

\section{Eucharassus chemsaki sp. nov.}

(Figs. 1, 2)

Etimologia. Homenagem ao renomado pesquisador John A. Chemsak (EMEC).

Macho. Cabeça castanho-escura ou avermelhada. Escapo, pedicelo e antenômeros III-VIII castanho-avermelhados com os ápices mais escuros; IX-XI pretos. Lados do protórax e prosterno castanho-avermelhados; pronoto preto. Mesosterno, metasterno e abdome castanho-escuros. Élitros (Fig. 1) castanhos e com três faixas, basal, mediana e apical, transversais e irregulares, de pilosidade esbranquiçada. Pernas castanho-escuras exceto pedúnculo dos fêmures, base das metatíbias e tarsômeros I, castanho-claros.

Corpo com aspecto robusto. Cabeça com pontos finos e densos; pilosidade curta, esparsa e amarela. Gula com pontos finos, rasos e esparsos. Genas com pêlos longos, esparsos, eretos e amarelados. Mandíbulas com ápices simples. Ligação entre os lobos oculares com duas fileiras de omatídios. Antenas ultrapassam os ápices elitrais no antenômero IX; escapo com pontos grossos e densos; III cerca de 1/3 mais longo que o escapo; III-VI com pilosidade longa, abundante e esbranquiçada; III-V subiguais em comprimento e $1 / 3$ mais longos que VI-X, também subiguais; XI 1/3 mais mais longo que o $\mathrm{X}$.

Protórax com pubescência dourada; margem posterior do protórax ligeiramente mais estreita que a anterior. Pronoto com 

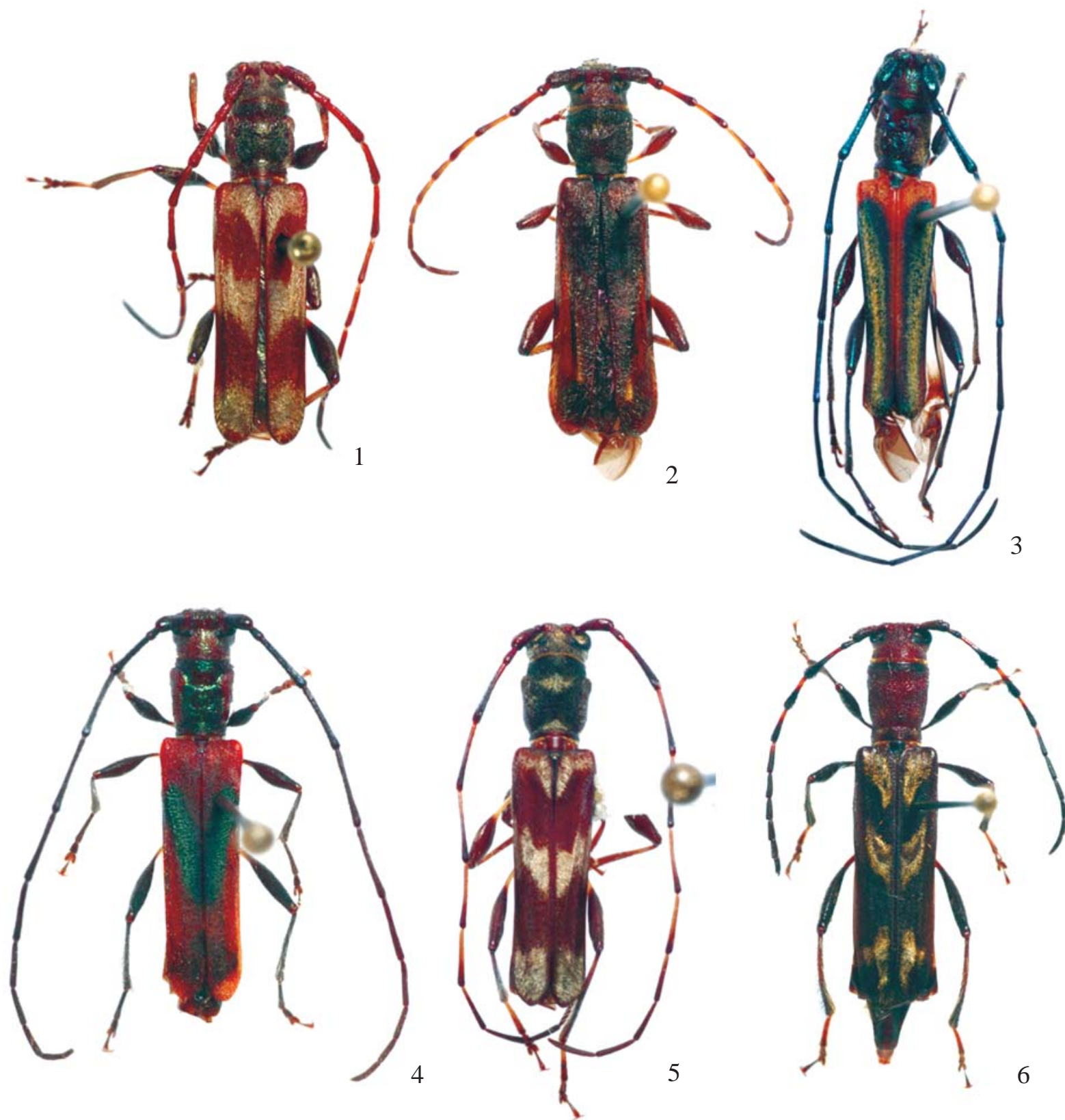

Figs. 1-6. 1-2, Eucharassus chemsaki sp. nov.: 1, holótipo macho, 16,2 mm; 2, parátipo fêmea, 14,8 mm; 3, E. hovorei sp. nov., holótipo macho, 15,8 mm; 4, E. lingafelteri sp. nov., 12,0 mm; 5-6, E. wappesi sp. nov.; 5, holótipo macho, 13,2 mm; 6, parátipo fêmea, 15,0 mm.

carena transversal mediana; pontuação grossa, irregular e densa; pêlos curtos, direcionados para região anterior; disco do pronoto elevado; margem posterior com estrias transversais. Prosterno com depressão circular mediana. Mesosterno e metasterno com pêlos longos, densos, eretos e esbranquiçados. Escutelo com pontos finos e densos. Élitros com pubescência castanha que recobre o tegumento exceto nas três faixas com pubescência esbranquiçada; ápices ligeiramente acuminados. Pernas com abundantes pêlos longos e dourados; metafêmures mais curtos que os ápices elitrais; tíbias densamente pontuadas; protarsômero I 1/3 mais longo que o II; mesotarsômero I o dobro do II; metatarsômero I 2,5 vezes o comprimento do II.

Abdome com pêlos longos, esparsos, eretos e amarelados.

Fêmea (Fig. 2). Cabeça e pernas castanho-avermelhadas. Escapo castanho-escuro com base avermelhada. Antenômeros bicolores: III-VI ou VIII alaranjados com ápices castanhoescuros, ou os III-VI pretos com a base alaranjada; VII ou IXXI pretos. Protórax castanho-escuro. Antenas apenas alcançam o meio dos élitros. Prosterno sem depressão. Último tergito recoberto pelos élitros.

Dimensões, em mm, macho/fêmea. Comprimento total, 16,2/ 
14,8; comprimento do protórax, 3,0/2,3; maior largura do protórax, 2,8/2,2; comprimento do élitro, 11,1/9,8; largura umeral, $3,2 / 2,9$.

Material-tipo. Holótipo macho, COSTA RICA, Alajuela: Vulcão Poas, $18 \mathrm{~km}$ nw Vara Blanca, 15.VII.1973, J. Doyen \& P. Opler col. (EMEC). Parátipos: COSTA RICA, Puntarenas: C. Chomogo, Monteverde, 1800m, macho, 1.IX.1996, M. A. Zumbado col. (MNRJ); San José: Parque Nacional Chirripó, Cuesta Los Arrepentidos, 32003300, 2 fêmeas, 27.V.2001, R. González col. (MNRJ; CASC).

Comentários. Os exemplares fêmeas estão um pouco danificados e as faixas dos élitros são pouco evidentes. Eucharassus chemsaki sp. nov. (Figs. 1,2) e E. wappesi sp. nov. (Figs. 5, 6) são as únicas espécies do gênero com três faixas transversais de pubescência nos élitros. Além dos caracteres da chave, E. chemsaki sp. nov. difere de E. wappesi sp. nov. por apresentar o prosterno, nos machos, com depressão circular mediana e último tergito não visível em vista dorsal; em $E$. wappesi sp. nov. o prosterno não tem depressão e último tergito, nas fêmeas, é visível em vista dorsal.

\section{Eucharassus hovorei sp. nov.}

(Fig. 3)

Etimologia. Homenagem póstuma ao amigo entomólogo Frank T. Hovore.

Cabeça, antenas, protórax, escutelo, mesosterno, metasterno e abdome castanho-escuros a pretos, com reflexo metálico azul ou verde. Élitros escuros com reflexos metálicos, azul-claro e escuro ou arroxeado e com uma faixa longitudinal de pêlos dourados ou esbranquiçados exceto na margem anterior e ao longo da sutura, nos $2 / 3$ basais, alaranjados e pubescência dourada pouco aparente. Pernas castanhoescuras ou pretas, com reflexo verde ou azul metálico; pedúnculo dos fêmures amarelados.

Corpo com aspecto estreito. Cabeça com pêlos curtos, esparsos e esbranquiçados. Dorso da cabeça e fronte com pontos finos e densos. Gula com pontos finos, rasos e esparsos. Genas com pêlos longos e amarelos. Mandíbulas com ápices bidenteados. Ligação entre os lobos oculares com uma ou duas fileiras de omatídios. Antenas ultrapassam os ápices elitrais no antenômero VII; escapo 1/3 mais curto que o III, com pontos grossos e densos; III-VI cerca de $1 / 3$ mais longos que o escapo e com pilosidade longa, abundante e preta; VII-XI subiguais e ligeiramente mais curtos que VI.

Protórax com pubescência dourada. Pronoto com pêlos longos e dourados; carena elevada, transversal, antemediana; margens, anterior e posterior, e faixa mediana longitudinal com superfície brilhante e estrias transversais. Mesosterno e metasterno com pubescência densa e pêlos longos, eretos e amarelados. Escutelo com pontos finos e densos. Élitros com ápices acuminados. Pernas com abundantes pêlos longos e pretos; metafêmures apenas alcançam os ápices elitrais; tíbias densamente pontuadas; protarsômero I 1/3 mais longo que o II; mesotarsômero I o dobro do II; metatarsômero I quase três vezes o comprimento do II.
Abdome com pêlos longos, esparsos e amarelados.

Fêmea. Antenas mais curtas, ultrapassando o ápice elitral no antenômero IX. Último tergito visível em vista dorsal.

Dimensões, em mm, macho/fêmea. Comprimento total, 15,8 10,5/16,0-13,8; comprimento do protórax, 3,2-1,5/2,7-1,8; maior largura do protórax, 1,9-1,2/2,0-1,4; comprimento do élitro, 10,26,4/11,2-10,7; largura umeral, 2,8-2,0/2,4-2,2.

Material-tipo. Holótipo macho, COSTA RICA, Puntarenas: Arenal, San Luís Monteverde, 1000-1350m, V.1994, Z. Fuentes col. (MNRJ). Parátipos. COSTA RICA, Cartago: Parque Nacional Barbilla, Cerro Tigre, 800-1200m, macho, 27-29.V.2003, E. Rojas col. (CASC); Guanacaste: estrada Cacao, 1000-1400m, lado sudoeste do vulcão Cacao, 2 fêmeas VI.1990 (MNRJ; CASC); Puntarenas: Estrada La Casona, Monteverde, 1520m, macho, VII.1993, N. Obando col (MNRJ); San José: Zurquí de Moravia, 1600m, macho, IV.1995, P. E. Hanson (CASC).

Comentários. Eucharassus hovorei sp. nov. (Fig. 3) aproxima-se de E. lingafelteri $\mathbf{s p . ~ n o v . ~ ( F i g . ~ 4 ) ~ p e l o ~ c o l o r i d o ~}$ metálico da cabeça e protórax e diferencia-se pelos caracteres descritos na chave.

\section{Eucharassus lingafelteri sp. nov.} (Fig. 4)

Etimologia. Homenagem ao estimado pesquisador Steven W. Lingafelter (USNM).

Tegumento de maneira geral castanho-avermelhado; cabeça, protórax, mesosterno, metasterno e abdome com reflexo metálico verde; antenas e pernas castanho-escuras exceto pedúnculo dos fêmures amarelos e tarsômeros III-V castanho-claros. Élitros vermelhos com faixa oblíqua antemediana verde metálica.

Corpo com aspecto estreito. Dorso da cabeça e fronte com pontos finos, irregulares e densos. Gula com pontos finos, rasos e densos. Genas com pêlos longos e amarelos. Mandíbulas bidenteadas no ápice. Ligação entre os lobos oculares com duas fileiras de omatídios. Antenas ultrapassam os ápices elitrais no antenômero VIII; escapo com pontos grossos e densos; III cerca de 1/3 mais longo que o escapo; III-VII subiguais em comprimento e com pilosidade longa, abundante e preta; VIII-X gradualmente mais curtos para o ápice; XI com comprimento subigual ao X.

Protórax com pubescência dourada. Pronoto com pêlos longos e dourados, carena elevada transversal no terço anterior; margens anterior e posterior no protórax e faixa mediana longitudinal no pronoto com reflexo verde metálico e estrias transversais. Mesosterno e metasterno com pubescência esbranquiçada. Escutelo com pontos finos e densos. Élitros com pêlos curtos, esparsos e alaranjados; ápices acuminados. Pernas com abundantes pêlos longos e pretos; metafêmures não alcançam os ápices elitrais; tíbias densamente pontuadas; protarsômero I $1 / 3$ mais longo que o II; mesotarsômero I o dobro do II; metatarsômero I quase três vezes o comprimento do II. Abdome com abundantes pêlos longos e esbranquiçados. 
Dimensões, em mm, macho. Comprimento total, 12,0; comprimento do protórax, 2,1; maior largura do protórax, 1,6; comprimento do élitro, 8,2; largura umeral, 2,2.

Material-tipo. Holótipo macho, PANAMÁ, Chiriquí: 6 km, SE, Fortuna, 15-17.V.1993, E. Giesbert col. (MNRJ).

\section{Eucharassus wappesi sp. nov.}

(Figs. 5, 6)

Etimologia. Homenagem ao estimado cerambicidólogo James E. Wappes (ACMT).

Macho. Cabeça castanho-escura exceto tubérculos anteníferos castanho-avermelhados. Escapo e pedicelo castanho-avermelhados; antenômeros III-VIII bicolores: III-V pretos com o terço basal castanho-avermelhado e os VI-VIII castanho-avermelhados em toda a metade basal; IX-XI pretos. Lados do protórax e prosterno castanho-avermelhados; pronoto preto. Mesosterno, metasterno e abdome castanhoescuros. Élitros castanho-escuros, com três faixas, basal, mediana e apical, transversais e irregulares, de pilosidade dourada. Pernas castanho-escuras exceto pedúnculo dos fêmures, base das metatíbias e tarsos, castanho-claros.

Corpo com aspecto estreito. Cabeça com pontos finos e densos; com pêlos curtos, densos, decumbentes e pêlos longos, esparsos, eretos e amarelados. Gula com pontos finos, rasos e esparsos. Mandíbulas com ápices bidenteados. Ligação entre os lobos oculares com duas fileiras de omatídios. Antenas ultrapassam os ápices elitrais no antenômero VII; escapo com pontos finos e densos; III cerca de 1,5 vezes mais longo que o escapo; III-VI com pilosidade longa, abundante e castanhoclara; III-X gradual e ligeiramente mais curtos para o ápice; XI tão longo quanto $X$.

Protórax com pubescência dourada; margem posterior do protórax distintamente mais estreita que a anterior. Pronoto com pontuação densa e fina; pêlos curtos, direcionados para região anterior e dourados; disco do pronoto elevado. Mesosterno e metasterno com pubescência densa, esbranquiçada e pêlos longos, esparsos, eretos e amarelados. Escutelo com pontos finos e densos. Élitros com pubescência castanho-escura que recobre o tegumento exceto nas três faixas com pubescência dourada; ápices ligeiramente acuminados. Pernas com abundantes pêlos longos e dourados; metafêmures quase alcançam os ápices elitrais; tíbias densamente pontuadas; protarsômero I 1/3 mais longo que o II; mesotarsômero I o dobro do II; metatarsômero I 2,5 vezes o comprimento do II. Abdome com pêlos longos, esparsos, decumbentes e amarelados.

Fêmea (Fig. 6). Cabeça e protórax castanho-avermelhados. Antenas curtas, alcançam o terço apical dos élitros; antenômeros III-IV com tufo de pêlos pretos na metade apical; III-VI bicolores, pretos com a base alaranjada; VII-XI pretos. Último tergito visível em vista dorsal.

Dimensões, em mm, macho/fêmea. Comprimento total, 13,2/ 15,0; comprimento do protórax, 2,5/2,9; maior largura do protórax, 2,0/2,2; comprimento do élitro, 8,9/10,4; largura umeral, $2,2 / 3,0$.

Material-tipo. Holotipo macho, PANAMÁ, Chiriquí: Finca La Suiza, 1220m, 5.VI.2000 H. \& A. Howden col. (USNM). Parátipo fêmea, GUATEMala, Eı Progresso: $27 \mathrm{~km} \mathrm{~N} \mathrm{La} \mathrm{Estancia,} \mathrm{7-}$ 9.V.1991, E. Giesbert col. (MNRJ).

\section{Comentários. Ver comentários de E. chemsaki.}

Agradecimentos. Ao Prof. José Ricardo M. Mermudes (UERJ) pela execução das fotos. Aos curadores das instituições pelo empréstimo do material.

\section{REFERÊNCIAS}

Aurivillius, C. 1891. Neue Coleoptera Longicornia. Entomologisk Tidskrift 12: 7-106.

Aurivillius, C. 1912. Coleopterorum Catalogus, pars 39, Cerambycidae: Cerambycinae. Berlin, W. Junk, 574 p.

Bates, H. W. 1885. Biologia Centrali-Americana, Insecta, Coleoptera, suppl. to Longicornia. London, 5: 249-436.

Galileo, M. H. M. \& Martins, U. R. 2001. Novos táxons e notas sobre Cerambycidae (Coleoptera) neotropicais. Iheringia, Série Zoologia, 90: 93-106.

Melzer, J. 1934. Novos subsidios para o conhecimento dos cerambycideos neotrópicos. Revista de Entomologia 4: 70-110.

Monné, M. A. 2005. Catalogue of the Cerambycidae (Coleoptera) of the Neotropical Region. Part I. Subfamily Cerambycinae. Zootaxa 946: $1-765$. 